\title{
Article \\ Facile Synthesis of Polyaniline/Carbon-Coated Hollow Indium Oxide Nanofiber Composite with Highly Sensitive Ammonia Gas Sensor at the Room Temperature
}

\author{
Sheng-Zhe Hong, Qing-Yi Huang and Tzong-Ming Wu *D \\ Department of Materials Science and Engineering, National Chung Hsing University, 250 Kuo Kuang Road, \\ Taichung 402, Taiwan; gsn30628@gmail.com (S.-Z.H.); jordan20310687@gmail.com (Q.-Y.H.) \\ * Correspondence: tmwu@dragon.nchu.edu.tw; Tel.: +886-4-2284-0500
}

check for updates

Citation: Hong, S.-Z.; Huang, Q.-Y.; Wu, T.-M. Facile Synthesis of Polyaniline/Carbon-Coated Hollow Indium Oxide Nanofiber Composite with Highly Sensitive Ammonia Gas Sensor at the Room Temperature. Sensors 2022, 22, 1570. https:// doi.org/10.3390/s22041570

Academic Editor: Nicole

Jaffrezic-Renault

Received: 4 January 2022

Accepted: 16 February 2022

Published: 17 February 2022

Publisher's Note: MDPI stays neutral with regard to jurisdictional claims in published maps and institutional affiliations.

Copyright: (C) 2022 by the authors. Licensee MDPI, Basel, Switzerland. This article is an open access article distributed under the terms and conditions of the Creative Commons Attribution (CC BY) license (https:// creativecommons.org/licenses/by/ $4.0 /)$.

\begin{abstract}
Hollow carbon-coated $\mathrm{In}_{2} \mathrm{O}_{3}\left(\mathrm{C \#} \mathrm{In}_{2} \mathrm{O}_{3}\right)$ nanofibers were prepared using an efficiently combined approach of electrospinning, high-temperature calcination, and hydrothermal process. The polyaniline (PANI) / hollow C\#In $\mathrm{O}_{3}$ nanofiber composites were synthesized used hollow $\mathrm{C} \mathrm{In}_{2} \mathrm{O}_{3}$ nanofibers worked as a core through the in situ chemical oxidative polymerization. The morphology and crystalline structure of the PANI/hollow $\mathrm{C \# In}{ }_{2} \mathrm{O}_{3}$ nanofiber composite were identified using wide-angle $\mathrm{X}$-ray diffraction and transmission electron microscopy. The gas-sensing performances of the fabricated PANI/hollow $\mathrm{C \# In}{ }_{2} \mathrm{O}_{3}$ nanofiber composite sensor were estimated at room temperature, and the response value of the composite sensor with an exposure of $1 \mathrm{ppm} \mathrm{NH}_{3}$ was 18.2, which was about 5.74 times larger than that of the pure PANI sensor. The PANI/hollow $\mathrm{C \# I}_{2} \mathrm{O}_{3}$ nanofiber composite sensor was demonstrated to be highly sensitive to the detection of $\mathrm{NH}_{3}$ in the concentration range of $0.6 \sim 2.0 \mathrm{ppm}$, which is critical for kidney or hepatic disease detection from the human breath. This composite sensor also displayed superior repeatability and selectivity at room temperature with exposures of 1.0 and $2.0 \mathrm{ppm} \mathrm{NH}_{3}$. Because of the outstanding repeatability and selectivity to the detection of $\mathrm{NH}_{3}$ at 1.0 and $2.0 \mathrm{ppm}$ confirmed in this investigation, the PANI/hollow $\mathrm{C \# In} \mathrm{In}_{3} \mathrm{O}_{3}$ nanofiber composite sensor will be considered as a favorable gas-sensing material for kidney or hepatic disease detection from human breath.
\end{abstract}

Keywords: polyaniline; hollow carbon-coated indium trioxide nanofiber; ammonia gas sensor; composite

\section{Introduction}

Human breath contains a mixture of nitrogen, oxygen, carbon dioxide, water, and other gas compounds occurring in concentrations ranging from a few ppt to thousands of ppm [1,2]. An adjustment in component is strongly reliant on several topics, for instance age, health condition, and gender. Among these gas compounds, ammonia $\left(\mathrm{NH}_{3}\right)$ is a breakdown product of protein, which is normally transferred into urea by the liver and exhausted through the kidneys. Therefore, the change of $\mathrm{NH}_{3}$ composition in human breath might show specific relationships regarding kidney or hepatic disease [3-7]. According to a previous study, the concentrations of $\mathrm{NH}_{3}$ of healthy human breath are numerous hundred ppb and significantly increase to several ppm during either kidney or hepatic collapses. During this work, Turner et al. [8] reported that a $\mathrm{NH}_{3}$ concentration larger than 1.6 ppm is identified be unhealthy, while less than $1.1 \mathrm{ppm}$ is considered as healthy. An intermediate concentration between the borderline concentration of unhealthy and healthy is regarded for charity. Consequently, $\mathrm{NH}_{3}$ gas sensors within the special limit are receiving a lot of attention.

Intrinsically conducting polymers (ICPs) containing the excellent electronic transfer between ICPs and gas molecules with increasing gas vapor adsorption have been applied as a key component for sensing applications [9]. Among ICPs, polyaniline (PANI) is widely 
used for sensing areas owing to its excellent responsivity to $\mathrm{NH}_{3}$, high conductivity, easy synthesis, remarkable doping/de-doping chemical reaction, and outstanding environmental stability [10]. According to previous investigations, the combination of metal oxide n-type semiconductors, such as $\mathrm{CeO}_{2}, \mathrm{In}_{2} \mathrm{O}_{3}, \mathrm{SnO}_{2}$, and $\mathrm{WO}_{3}$, or carbon-based materials into PANI can enhance the stability, sensitivity, and repeatability of the sensor nanocomposite sensor [11-14]. Xue et al. [12] reported a PANI/carbon nanotube (CNT) composite showed enhanced sensing performance and stability at room temperature as compared to that of pure PANI. Li et al. [14] prepared a composite sensor with improved sensing performance at room temperature using PANI and flower-like $\mathrm{WO}_{3}$ with higher special surface area. Recently, Wu et al. [15] used $\mathrm{In}_{2} \mathrm{O}_{3}$ nanoparticles, graphene nanoribbon (GNR), and PANI to synthesize a composite sensor containing nanostructured conformation. These results revealed that the sensing properties at room temperature were considerably greater than those of pure PANI and PANI/GNR composite sensor. Recently, Wu et al. [16] applied a high special surface area hollow $\mathrm{In}_{2} \mathrm{O}_{3}$ nanofiber, nitrogen-doped graphene quantum dot (N-GQD), and PANI to synthesize a ternary composite. Their results revealed that the sensing properties of composite sensor at room temperature were greater than those of PANI/hollow $\mathrm{In}_{2} \mathrm{O}_{3}$ nanofiber composites. The superior gas-sensing performances were attributed to the formation of $\mathrm{p}-\mathrm{n}$ junction between the $\mathrm{p}$-type PANI and n-type high special surface area hollow $\mathrm{In}_{2} \mathrm{O}_{3}$ nanofiber with increasing electron depletion layer, as well as the sensing response.

This work describes a simple fabrication of PANI/hollow carbon-coated $\operatorname{In}_{2} \mathrm{O}_{3}\left(\mathrm{C \#} \mathrm{In}_{2} \mathrm{O}_{3}\right)$ nanofiber as an electrode employed as gas-sensing material to detect ammonia in the concentration range of $0.6 \sim 2.0 \mathrm{ppm}$ from the human breath. To our knowledge, no report on PANI and carbon-coated surface of $\mathrm{In}_{2} \mathrm{O}_{3}$ nanofiber composite with one-step process and larger special surface area has been published. Consequently, the synthesized material is anticipated to show bettered gas-sensing properties and exceptional repeatability and selectivity. The structure, morphology, and gas-sensing performances of the manufactured composites are considerably characterized in the following discussion.

\section{Experimental}

\subsection{Materials}

Polyvinylpyrrolidone (PVP), isopropyl alcohol (>98\%), and ammonium persulfate (APS, >98\%) were obtained from JT-Baker Chemical Company (Phillipsburg, NJ, USA). Indium(III) nitrate hydrate $\left(\operatorname{In}\left(\mathrm{NO}_{3}\right)_{3},>99.9 \%\right)$, citric acid $(\mathrm{CA},>98 \%)$, sulfuric acid $(>98 \%)$, urea $(>98 \%)$, and aniline monomer were purchased from Sigma-Aldrich Chemical Company (St. Louis, MO, USA). All chemicals were utilized as received.

\subsection{Synthesis of Polyaniline/Carbon-Coated Hollow Indium Trioxide Nanofiber Composites}

The hollow $\mathrm{In}_{2} \mathrm{O}_{3}$ nanofibers were prepared using indium nitrate hydrate as indium source. In a usual preparation process, $1.1 \mathrm{~g} \operatorname{In}\left(\mathrm{NO}_{3}\right)_{3}$ and $3.5 \mathrm{~g}$ PVP were mixed in 10.6 mL DMF and $12 \mathrm{~mL}$ ethyl alcohol, and the solution was stirred to completely dissolve $\mathrm{In}\left(\mathrm{NO}_{3}\right)_{3}$ and PVP for $10 \mathrm{~h}$. Then, the mixed solution was loaded into a $20 \mathrm{~mL}$ syringe containing a metallic needle with $0.5 \mathrm{~mm}$ diameter for electrospinning process $[17,18]$. The tip of the metallic needle was applied to $20 \mathrm{kV}$ high-voltage power with a feeding rate of $0.3 \mathrm{~mL} / \mathrm{h}$, and the distance between the collector and the needle was approximately $15 \mathrm{~cm}$. Following the electrospinning process for $24 \mathrm{~h}$, the fabricated as-spun nanofiber was thermally calcinated for $3 \mathrm{~h}$ at $800^{\circ} \mathrm{C}$ with a heating rate of $5^{\circ} \mathrm{C} / \mathrm{min}$ to prepare hollow $\mathrm{In}_{2} \mathrm{O}_{3}$ nanofibers.

For the hydrothermal synthesis of the core-shell structure of carbon-coated hollow

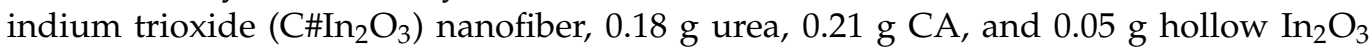
nanofiber were mixed under stirring in a $10 \mathrm{~mL}$ beaker for $30 \mathrm{~min}$ at room temperature. Then the mixed solution was loaded into a poly(tetrafluoroethylene) reactor and heated for $4 \mathrm{~h}$ at $160{ }^{\circ} \mathrm{C}$. The obtained products were further modified by adding ethanol into the solution and centrifuging for $2 \mathrm{~h}$ at $5000 \mathrm{rpm}$ to attain the $\mathrm{C} \# \mathrm{In}_{2} \mathrm{O}_{3}$ samples. The fabricated 
product was washed by distilled water (DI water) and consequently purified using dialysis bag for $24 \mathrm{~h}$.

In situ chemical oxidative polymerization was used to synthesize the polyaniline

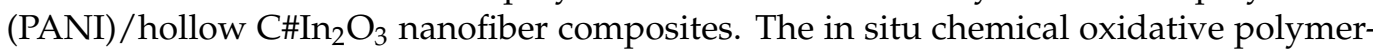
ization mechanism of PANI can be divided into two steps. First, the aniline monomer is oxidized to form cationic radicals followed by free radical polymerization. The achieved aniline dimer consequently experiences a deprotonation process, resulting in an active neutral dimer, which facilitates the dimer to react in the following oxidation process. This process is repeated, leading eventually to the formation of PANI. In a typical preparation process, a certain weight ratio of hollow $\mathrm{C \# In}{ }_{2} \mathrm{O}_{3}$ nanofiber was dispersed in $50 \mathrm{~mL}$ $\mathrm{HCl}$ solution and sonicated for $2 \mathrm{~h}$. Consequently, the aniline monomer was added into the dispersed solution of the hollow $\mathrm{C} \# \operatorname{In}_{2} \mathrm{O}_{3}$ nanofiber and stirred for $1 \mathrm{~h}$. The APS was then dissolved in $20 \mathrm{~mL} \mathrm{HCl}$ solution and was slowly added into the mixed aniline monomer/hollow C\#In ${ }_{2} \mathrm{O}_{3}$ nanofiber solution. The reactants were polymerized at $0{ }^{\circ} \mathrm{C}$ for $3 \mathrm{~h}$. The obtained product was filtered, washed several times with DI water and methanol, and vacuum dried at $60{ }^{\circ} \mathrm{C}$ for $24 \mathrm{~h}$. The yield of sample preparation is about $86 \%$.

\subsection{Material Characterization}

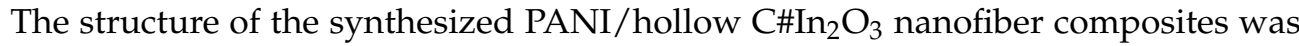
measured by wide-angle X-ray diffraction (WAXD) and Fourier transform infrared (FTIR). WAXD measurements operated using X-ray diffractometer (Bruker D8, BRUKER AXS, Inc., Madison, WI, USA) with a Ni-filtered $\mathrm{Cu} \mathrm{K} \alpha$ radiation were recorded at $2 \theta$ ranging from $1.5^{\circ}$ to $40^{\circ}$ with an increment of $1^{\circ} / \mathrm{min}$. FTIR spectra in a range of $400-4000 \mathrm{~cm}^{-1}$ were determined using a Perkin-Elmer Spectrum One spectrometer (Waltham, MA, USA). The morphology of all specimens was characterized by transmission electron microscopy (TEM) and field-emission scanning electron microscopy (FESEM). The TEM experiment was measured by JEOL JEM-2010 (JEOL Ltd., Tokyo, Japan). Specimens of TEM experiments were made by a Reichert Ultracut ultramicrotome. The FESEM measurement was performed by a JEOL JSM-6700F field-emission instrument (JEOL Ltd., Tokyo, Japan). Gold was used to coat the surface of all samples to avoid charging. Raman spectra were recorded under a Renishaw system 1000 using an Argon ion laser operating at $514.5 \mathrm{~nm}$ with a CCD detector. The BET and BJH methods using gas sorption analyzer (Quantachrome AutoSorb IQ, Montgomeryville, PA, USA) were used to determine the specific surface area obtained using $\mathrm{N}_{2}$ sorption isotherms.

\subsection{Gas-Sensing Properties}

The gas-sensing performance of the sensors was determined at $25^{\circ} \mathrm{C}$ using a homemade dynamic test system with a simultaneous resistance acquisition stage. The gas concentrations of interfering gas samples including $\mathrm{CH}_{3} \mathrm{OH}, \mathrm{C}_{2} \mathrm{H}_{5} \mathrm{OH}, \mathrm{C}_{3} \mathrm{H}_{6} \mathrm{O}$, and $\mathrm{C}_{6} \mathrm{H}_{14}$ and targeting $\mathrm{NH}_{3}$ sample were determined by changing the test samples and nitrogen mixing ratio. The equation of $R=R_{g} / R_{a}$ is used to calculate the sensor response, where $R_{g}$ and $R_{a}$ are the sensor resistances in test gases and air, respectively. The sensitivity is obtained from the slope of the response-concentration fitting curve.

\section{Results}

\subsection{Structural and Morphological Characterizations}

The characteristic SEM micrographs of hollow $\operatorname{In}_{2} \mathrm{O}_{3}$ and $\mathrm{C \# In}{ }_{2} \mathrm{O}_{3}$ nanofibers are illustrated in Figure 1a. The hollow $\operatorname{In}_{2} \mathrm{O}_{3}$ nanofiber displays a continuous hollow and fibrous morphology with coarse surface. After carbon-coating the surface of the hollow $\operatorname{In}_{2} \mathrm{O}_{3}$ nanofiber, the particle-like morphology is observed, and the surface becomes rougher. The average diameter of the hollow $\mathrm{In}_{2} \mathrm{O}_{3}$ nanofiber was about $165 \mathrm{~nm}$ and was slightly increased to $190 \mathrm{~nm}$ for the hollow $\mathrm{C} \# \mathrm{In}_{2} \mathrm{O}_{3}$ nanofiber. The WAXD technique was used to characterize the crystalline structure of the hollow $\operatorname{In}_{2} \mathrm{O}_{3}$ and $\mathrm{C \#} \operatorname{In}_{2} \mathrm{O}_{3}$ nanofibers. Both WAXD diffraction profiles of hollow $\operatorname{In}_{2} \mathrm{O}_{3}$ and $\mathrm{C \# In}{ }_{2} \mathrm{O}_{3}$ nanofibers, as exhibited in 
Figure $1 \mathrm{~b}$, present five intense diffraction peaks at $2 \theta=21.7^{\circ}, 30.6^{\circ}, 35.4^{\circ}, 51.2^{\circ}$, and $60.7^{\circ}$, designated to (211), (222), (400), (440), and (622) planes of crystalline $\mathrm{In}_{2} \mathrm{O}_{3}$, respectively. This result recommends that the crystalline structure of hollow $\operatorname{In}_{2} \mathrm{O}_{3}$ nanofibers is determined to be a cubic crystal phase [15], and the carbon-coated process did not change

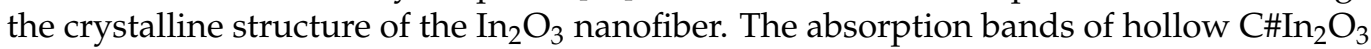
nanofiber obtained by using the Raman spectra were presented in Figure 1c. Two intense absorption peaks at $1587 \mathrm{~cm}^{-1}\left(\mathrm{G}\right.$ mode) and at $1345 \mathrm{~cm}^{-1}$ (D mode) are obtained in this figure. The $\mathrm{I}_{\mathrm{D}} / \mathrm{I}_{\mathrm{G}}$ ratio is 1.71 , which indicates that an amorphous structure of carbon-coated material was obtained.
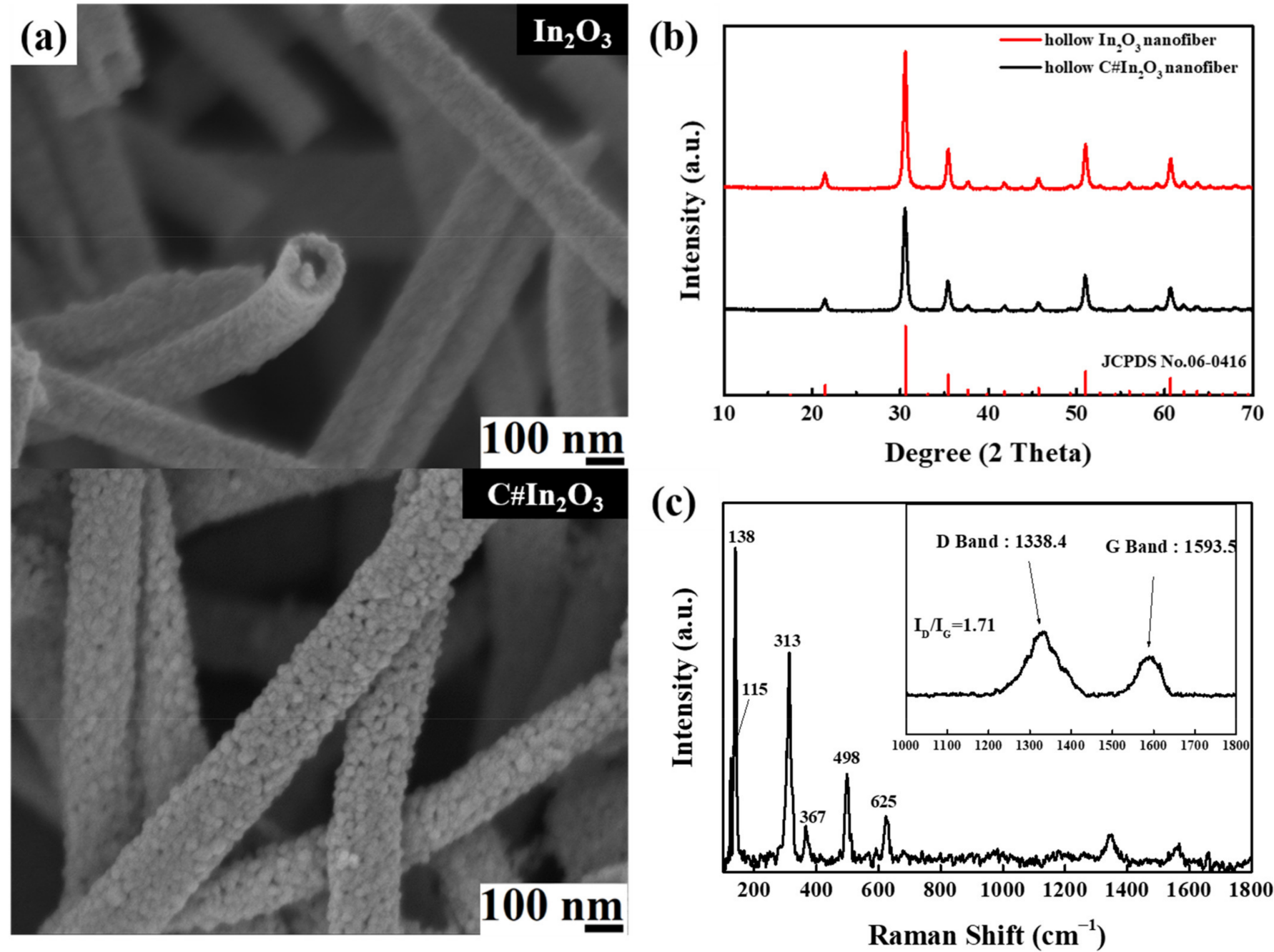

Figure 1. (a) SEM images of hollow $\operatorname{In}_{2} \mathrm{O}_{3}$ and C\#In ${ }_{2} \mathrm{O}_{3}$ nanofibers, (b) WAXD data of hollow $\operatorname{In}_{2} \mathrm{O}_{3}$ and $\mathrm{C \#} \operatorname{In}_{2} \mathrm{O}_{3}$ nanofibers, and (c) Raman spectra of hollow and $\mathrm{C \#} \operatorname{In}_{2} \mathrm{O}_{3}$ nanofibers.

In order to identify the carbon-coated morphology of $\mathrm{C} \# \operatorname{In}_{2} \mathrm{O}_{3}$ nanofiber, the highresolution TEM with nano beam diffraction (NBD) mode shown in Figure 2 was applied to obtain these evidence. From Figure $2 a, b$, it is clear that there is a thin layer with lower electron density coated on the surface of higher electron density material, which is identified as the carbon-coated material and $\mathrm{In}_{2} \mathrm{O}_{3}$ nanofiber, respectively. In addition, the microstructure of carbon-coated material and $\mathrm{In}_{2} \mathrm{O}_{3}$ nanofiber were further identified by NBD, as illustrated in Figure 2c-e. From the interface of the hollow $\operatorname{In}_{2} \mathrm{O}_{3}$ nanofiber, as shown in Figure 2c, there are a lot of diffraction spots. These results indicate that the microstructure of hollow $\mathrm{In}_{2} \mathrm{O}_{3}$ nanofibers is crystalline, which is consistent with the WAXD data. As the nano beam diffraction focuses to the lower electron density layer, 
as shown in Figure 2e, few diffraction spots are observed. This result indicates that the microstructure of carbon-coated material is amorphous, which is consistent with the Raman

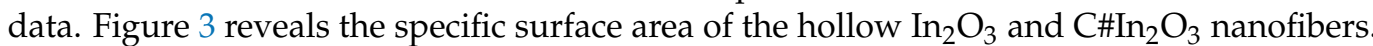
The data of the specific surface area for the hollow $\mathrm{In}_{2} \mathrm{O}_{3}$ and $\mathrm{C \#} \operatorname{In}_{2} \mathrm{O}_{3}$ nanofibers are 39.6 and $55.2 \mathrm{~m}^{2} \mathrm{~g}^{-1}$, respectively. The specific surface area significantly increases with the carbon-coated materials on the surface of the hollow $\operatorname{In}_{2} \mathrm{O}_{3}$ nanofiber. This observation suggests that the carbon-coated hollow $\mathrm{In}_{2} \mathrm{O}_{3}$ nanofibers would provide more reaction site for further interaction.

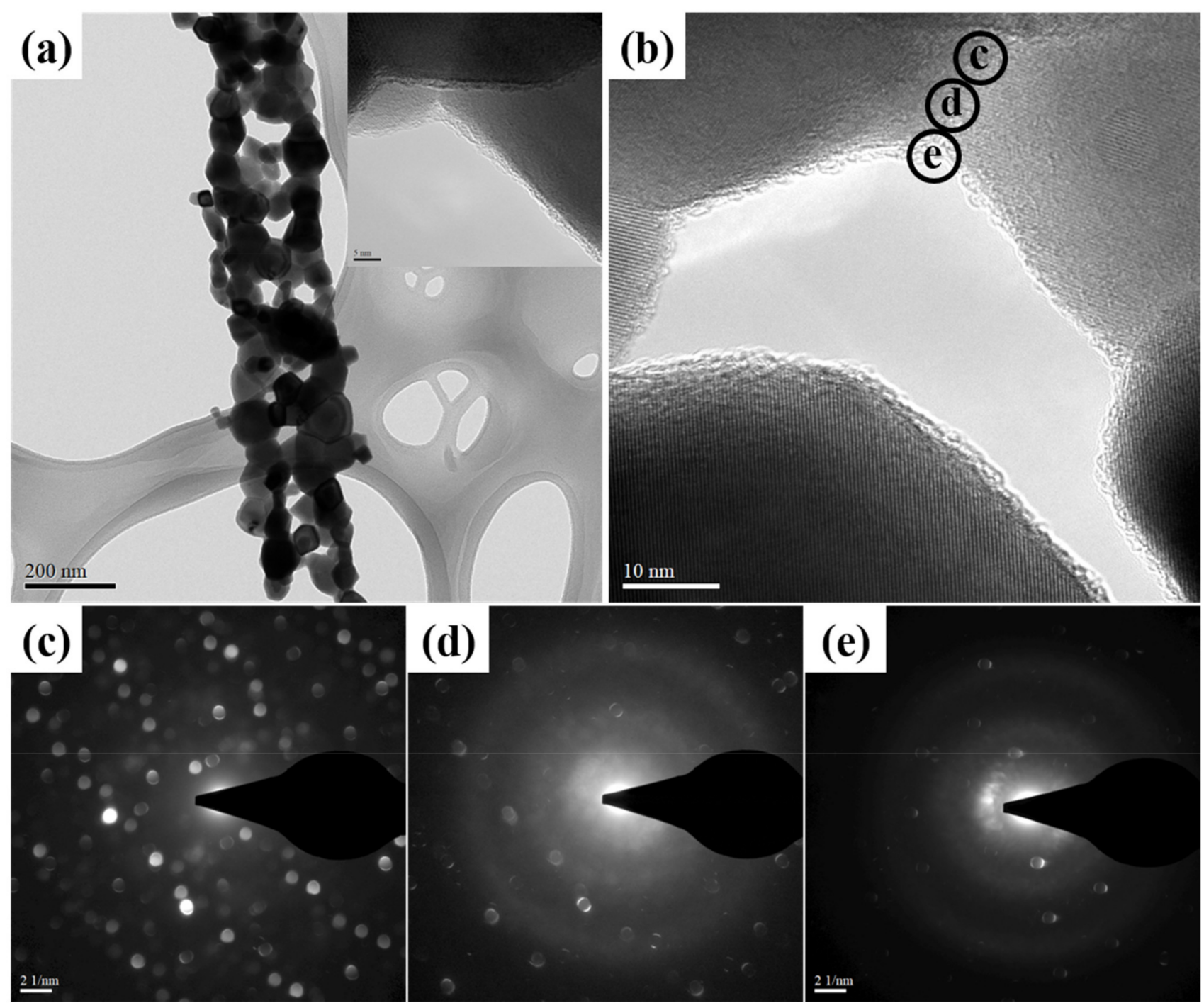

Figure 2. (a) TEM image of hollow $\mathrm{C \# In} \mathrm{O}_{3} \mathrm{O}_{3}$ nanofibers. (b) High-magnification TEM image of hollow $\mathrm{C \# In} \mathrm{O}_{3} \mathrm{O}_{3}$ nanofibers. Nano beam diffraction (NBD) images of selected area (c-e) in Figure $2 b$.

The FT-IR and TEM methods were used to characterize the chemical structure and morphology of the synthesized polyaniline (PANI) coated on the surface of hollow $\operatorname{In}_{2} \mathrm{O}_{3}$

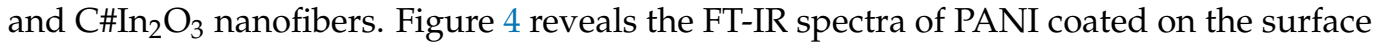
of hollow $\mathrm{In}_{2} \mathrm{O}_{3}$ and $\mathrm{C \# In} \mathrm{O}_{3}$ nanofiber composites. The FT-IR data of pure PANI and hollow $\mathrm{In}_{2} \mathrm{O}_{3}$ nanofiber are also displayed in this figure. The characteristic peaks of hollow $\mathrm{In}_{2} \mathrm{O}_{3}$ nanofiber observed at 538,567, and $600 \mathrm{~cm}^{-1}$ contributed to the In-O-In stretching vibration. The absorption peak of PANI occurring at $1240 \mathrm{~cm}^{-1}$ was ascribed to the $\mathrm{C}-\mathrm{N}^{\bullet+}$ stretching vibration, and the characteristic peak at $800 \mathrm{~cm}^{-1}$ was attributed to a C-H out-ofplane bending vibration of the 1,4-disubstituted aromatic rings [19]. The absorption peaks of $\mathrm{C}=\mathrm{N}$ and $\mathrm{C}-\mathrm{N}$ stretching vibrations were obtained at 1112 and $1294 \mathrm{~cm}^{-1}$, respectively. 


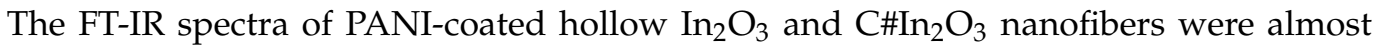
indistinguishable to those of neat PANI, suggesting that the surface of the hollow $\operatorname{In}_{2} \mathrm{O}_{3}$ and $\mathrm{C \# In} \mathrm{In}_{2} \mathrm{O}_{3}$ nanofibers was coated with PANI to form PANI/hollow $\operatorname{In}_{2} \mathrm{O}_{3}$ nanofiber and PANI/hollow C\# $\mathrm{In}_{2} \mathrm{O}_{3}$ nanofiber composites.

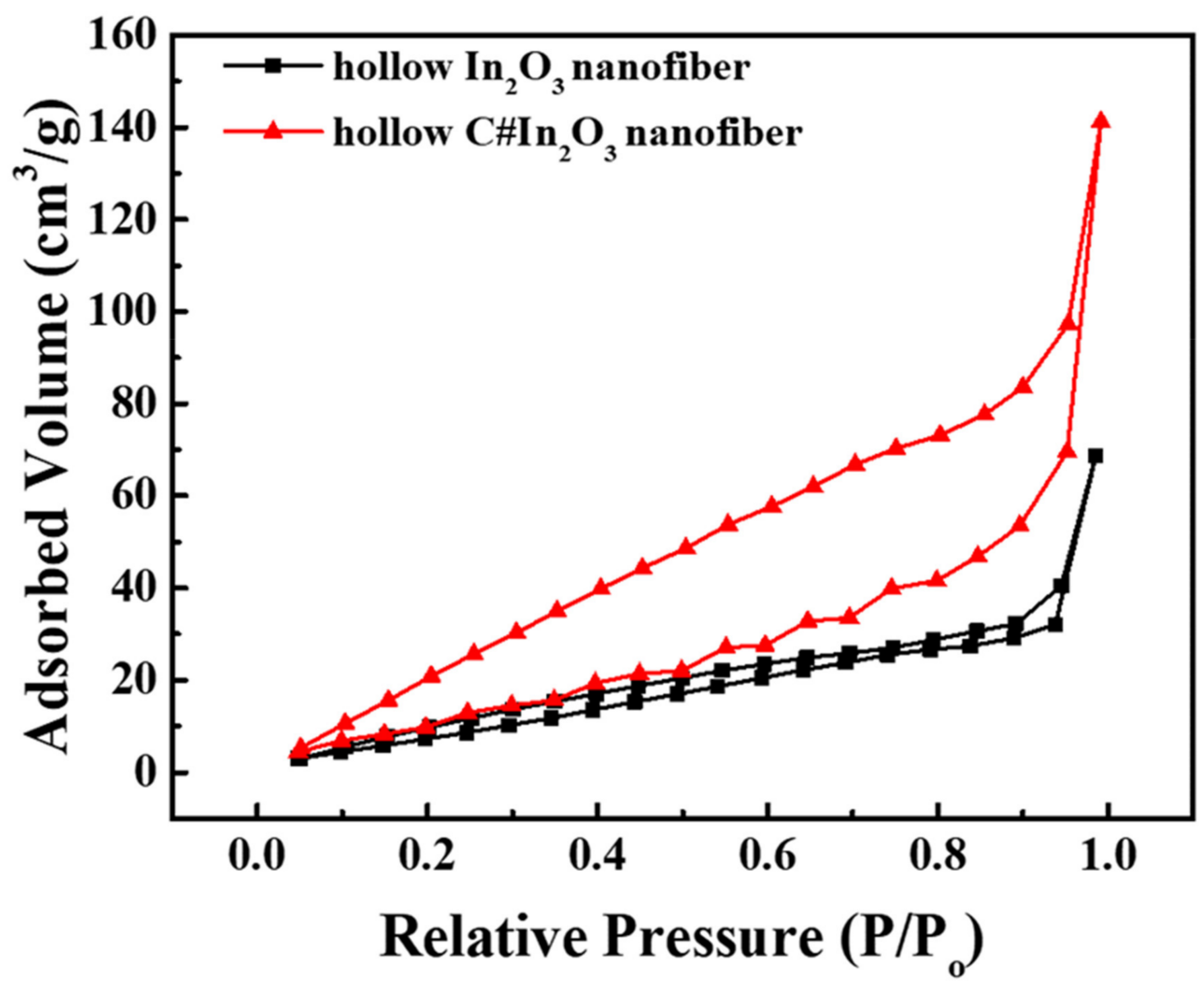

Figure 3. The BET curves of hollow $\operatorname{In}_{2} \mathrm{O}_{3}$ and $\mathrm{C \#} \operatorname{In}_{2} \mathrm{O}_{3}$ nanofibers.

Figure 5 shows the TEM images of PANI/hollow $\operatorname{In}_{2} \mathrm{O}_{3}$ nanofiber and PANI/hollow $\mathrm{C \# In} \mathrm{O}_{3}$ nanofiber composites. By coating conductive PANI on the surface of the hollow $\mathrm{In}_{2} \mathrm{O}_{3}$ and $\mathrm{C \# In} \mathrm{In}_{3}$ nanofiber, the diameters of the PANI/hollow $\mathrm{In}_{2} \mathrm{O}_{3}$ nanofiber and PANI/hollow C\#In $\mathrm{O}_{3}$ nanofiber composites were slightly increased, compared to the hollow $\mathrm{In}_{2} \mathrm{O}_{3}$ and $\mathrm{C} \# \mathrm{In}_{2} \mathrm{O}_{3}$ nanofiber. The diameters of the fabricated composites increased from $165 \mathrm{~nm}$ and $190 \mathrm{~nm}$ for hollow $\mathrm{In}_{2} \mathrm{O}_{3}$ and C\# $\mathrm{In}_{2} \mathrm{O}_{3}$ nanofiber to 190 and $220 \mathrm{~nm}$ for PANI/hollow $\mathrm{In}_{2} \mathrm{O}_{3}$ nanofiber and PANI/hollow C\#In $\mathrm{O}_{3}$ nanofiber composites, respectively. The increasing diameter in the fabricated composites can be attributed to a thin

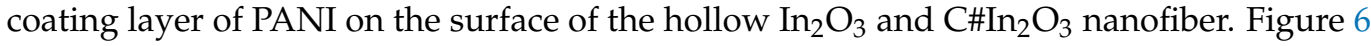
reveals the specific surface area of the PANI/hollow $\operatorname{In}_{2} \mathrm{O}_{3}$ nanofiber and PANI/hollow $\mathrm{C \# In}{ }_{2} \mathrm{O}_{3}$ nanofiber composites. The data of the specific surface area for the PANI/hollow

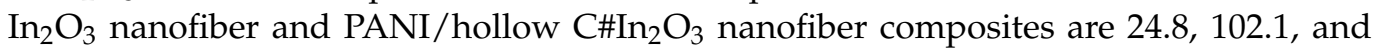
$111.6 \mathrm{~m}^{2} \mathrm{~g}^{-1}$. The specific surface area of both composite sensors is significantly higher than that of pure polymer matrix sensor. The specific surface area of PANI/hollow $\mathrm{C \# In}_{2} \mathrm{O}_{3}$ nanofiber composite is relatively higher than that of PANI/hollow $\operatorname{In}_{2} \mathrm{O}_{3}$ nanofiber compos-

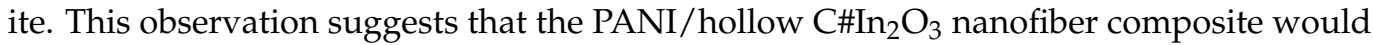
provide more reaction site for further interaction, compared to that of the PANI/hollow $\mathrm{In}_{2} \mathrm{O}_{3}$ nanofiber composite. 


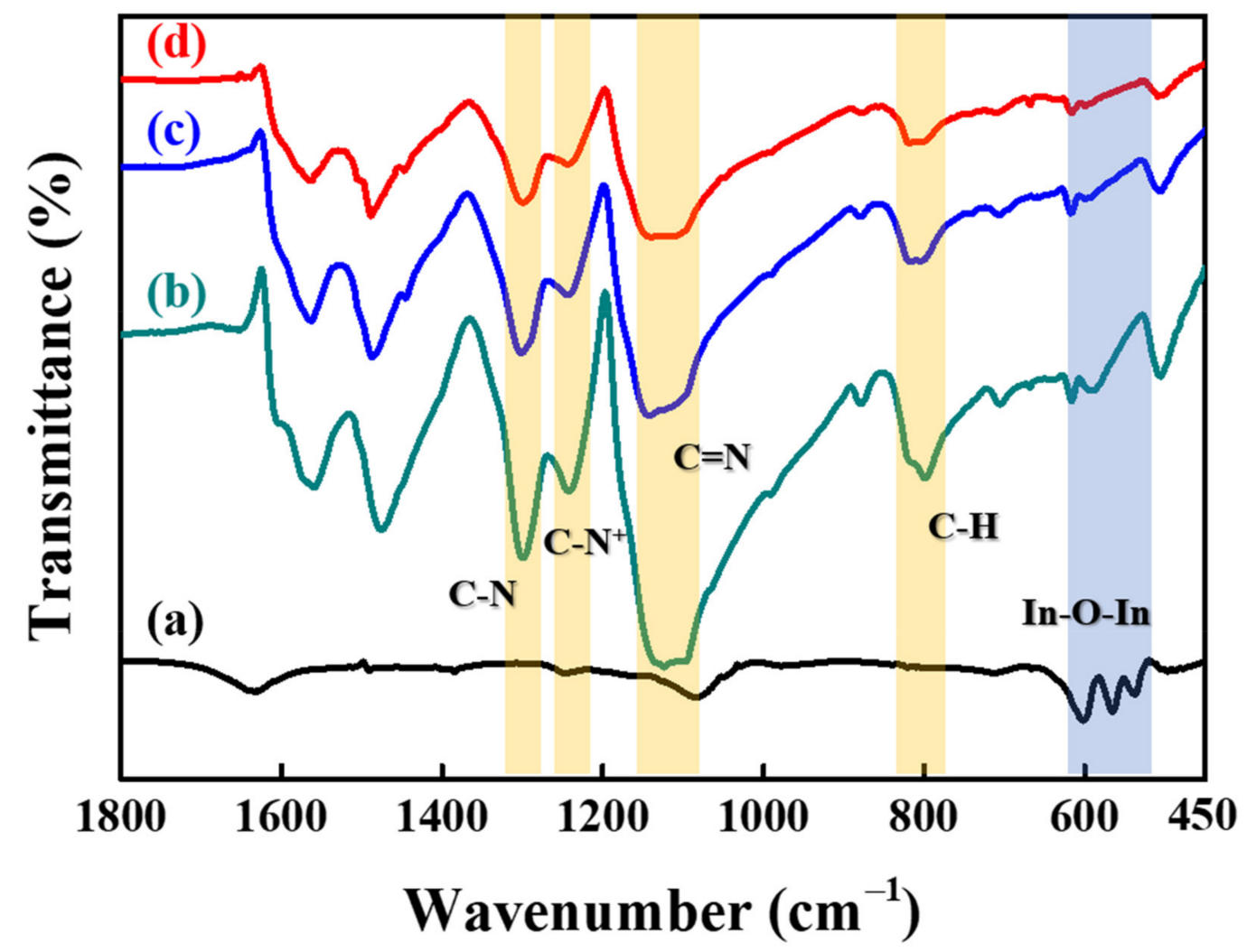

Figure 4. FT-IR spectra of (a) hollow $\mathrm{In}_{2} \mathrm{O}_{3}$ nanofiber, (b) pure PANI matrix, (c) PANI/hollow $\operatorname{In}_{2} \mathrm{O}_{3}$ nanofiber, and (d) PANI/hollow $\mathrm{C} \# \mathrm{In}_{2} \mathrm{O}_{3}$ nanofiber composites.

(a)
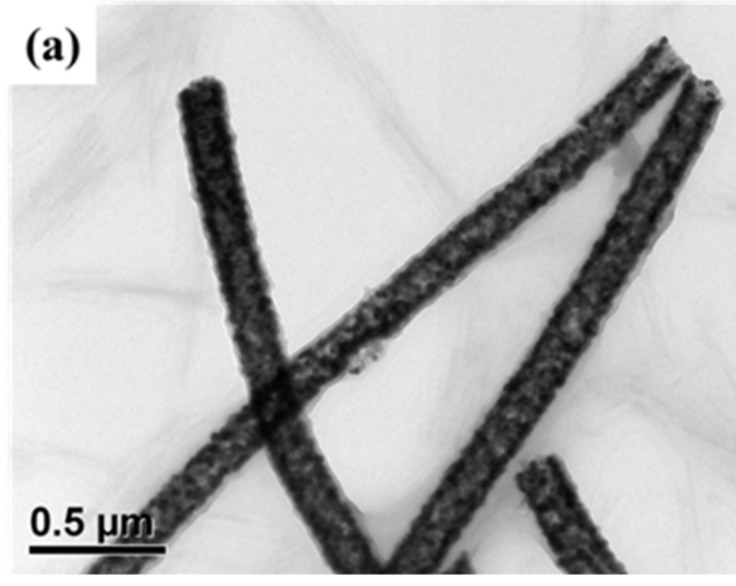

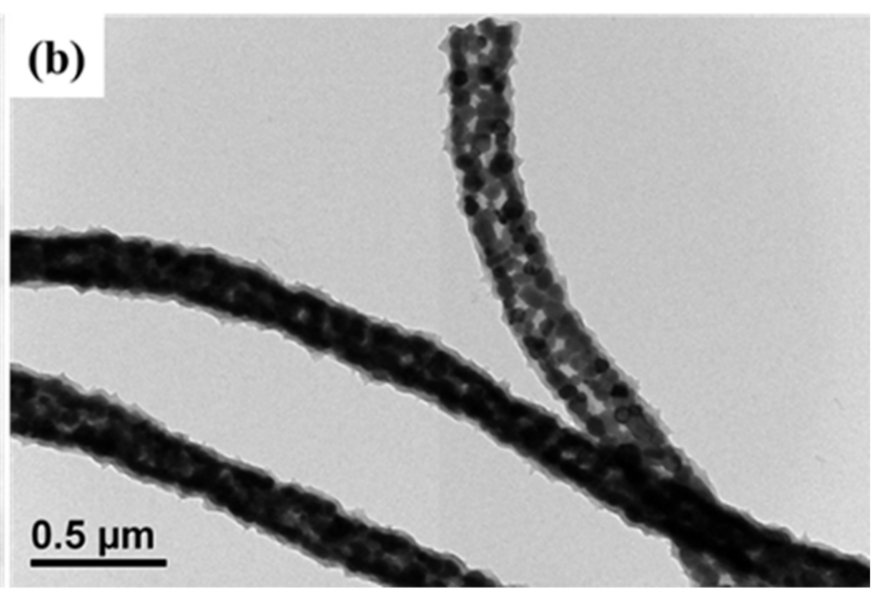

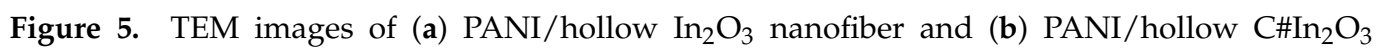
nanofiber composites. 


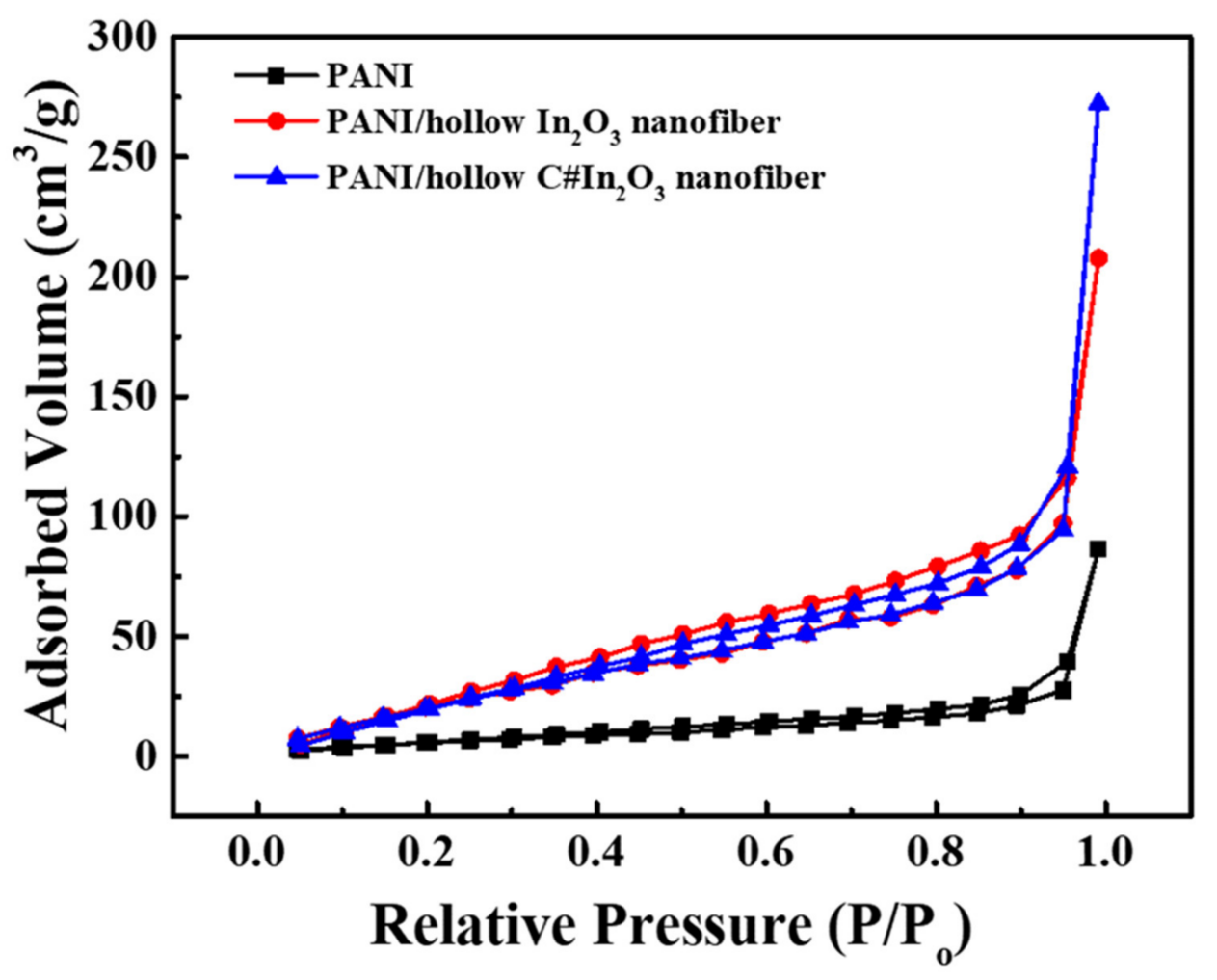

Figure 6. The BET profiles of PANI, PANI/hollow $\mathrm{In}_{2} \mathrm{O}_{3}$ nanofiber, and PANI/hollow $\mathrm{C \# In}_{2} \mathrm{O}_{3}$ nanofiber.

\section{2. $\mathrm{NH}_{3}$-Sensing Performance}

In order to evaluate the effect of carbon-coated material on the surface of hollow $\mathrm{In}_{2} \mathrm{O}_{3}$ nanofiber on the $\mathrm{NH}_{3}$-sensing property of the composite sensor, the response and recovery of PANI, PANI/hollow $\mathrm{In}_{2} \mathrm{O}_{3}$ nanofiber, and PANI/hollow C\# $\operatorname{In}_{2} \mathrm{O}_{3}$ nanofiber sensors were completely examined. Figure 7 shows the dynamic response-recovery profiles of the PANI and composite sensors with exposure to $1 \mathrm{ppm} \mathrm{NH}_{3}$ at room temperature. These results indicated that all sensors reacted with a significant improvement in resistance when exposed to $\mathrm{NH}_{3}$, and the resistance fell down to the initial situation after the $\mathrm{NH}_{3}$ was switched to dry air. This outcome displays a representative performance and an excellent reversibility of the composite sensors. Exceptionally, the PANI/hollow\# $\operatorname{In}_{2} \mathrm{O}_{3}$ nanofiber sensor demonstrated extremely greater response values than the pure PANI and PANI/hollow $\mathrm{In}_{2} \mathrm{O}_{3}$ nanofiber sensor, suggesting that hollow $\mathrm{C \#} \operatorname{In}_{2} \mathrm{O}_{3}$ nanofiber performs a dominant role in $\mathrm{NH}_{3}$-sensing measurements. The response values of pure PANI, PANI/hollow $\mathrm{In}_{2} \mathrm{O}_{3}$ nanofiber, and PANI/hollow $\mathrm{C} \# \mathrm{In}_{2} \mathrm{O}_{3}$ nanofiber sensors were about 3.6, 11.2, and 18.2, respectively. The response value of the previous investigation using PANI/N-GQD/hollow $\mathrm{In}_{2} \mathrm{O}_{3}$ nanofiber was 15.6 [16]. It is clear that the surface coated by a thin carbon layer showed a better gas sensing property. The enhancement of the sensing properties was assigned to the presence of a $\mathrm{p}-\mathrm{n}$ heterojunction generated between

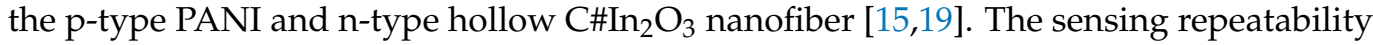
and reversibility of the PANI, PANI/hollow $\mathrm{In}_{2} \mathrm{O}_{3}$ nanofiber, and PANI/hollow $\mathrm{C \#}_{2} \mathrm{In}_{2} \mathrm{O}_{3}$ nanofiber sensors to $1.0 \mathrm{ppm} \mathrm{NH}_{3}$ are presented in Figure $7 \mathrm{~b}$. The response values of all gas sensors dropped down to the initial response value after exposure to $1.0 \mathrm{ppm}^{\mathrm{NH}_{3}}$. In the process of five continuous cycles, this typical behavior of response and recovery to $1.0 \mathrm{ppm} \mathrm{NH}_{3}$ approved exceptional reproducibility. This result suggests that the good repeatability of the PANI/hollow $\mathrm{C} \# \mathrm{In}_{2} \mathrm{O}_{3}$ nanofiber sensor is achieved. 


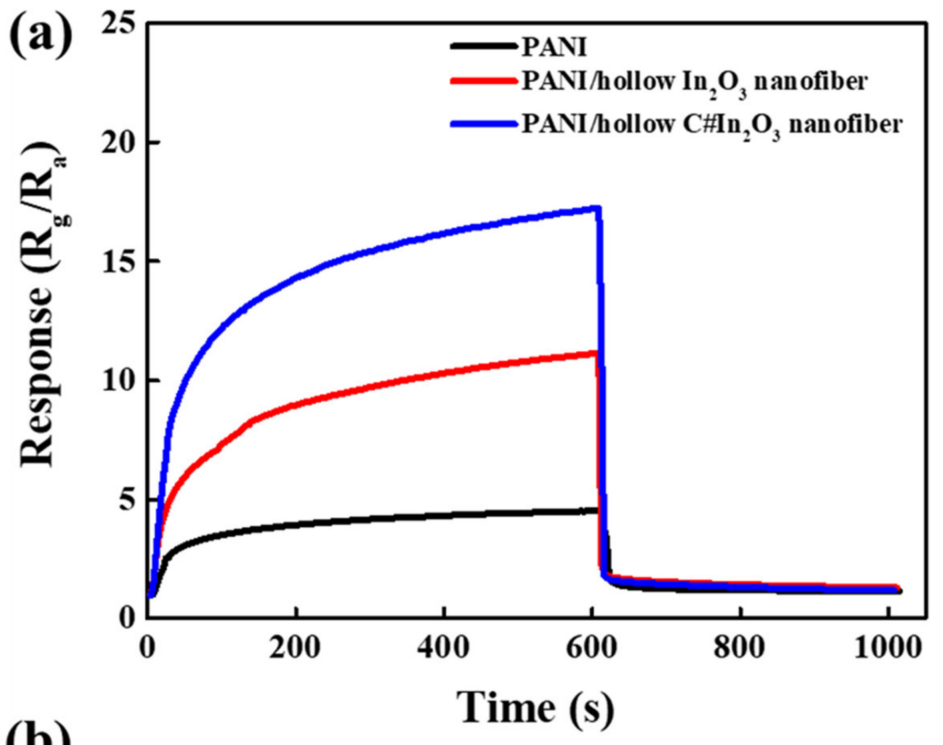

(b)

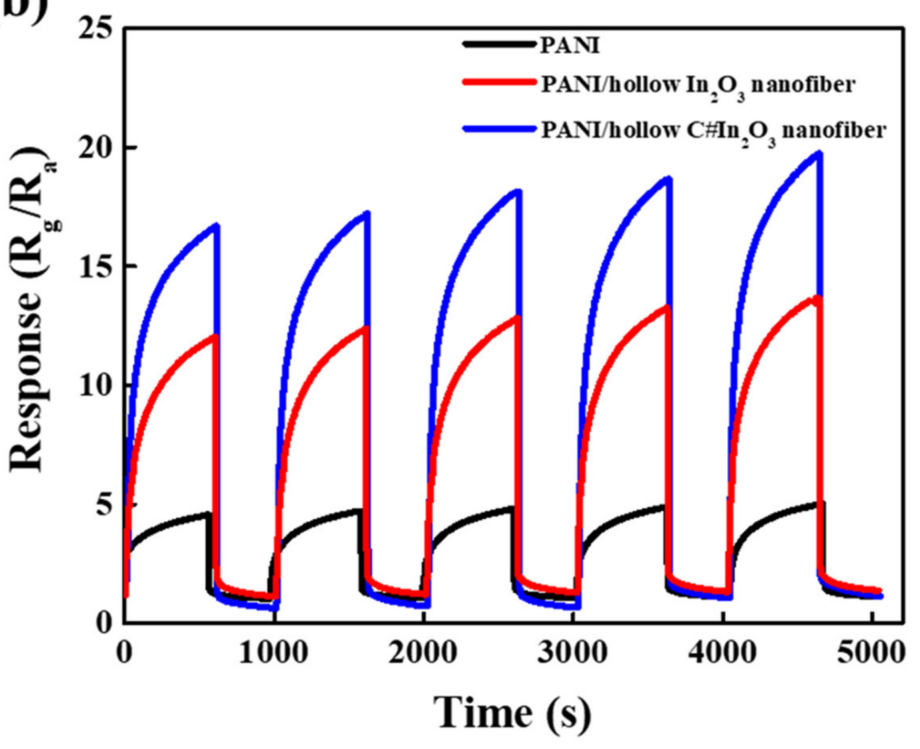

Figure 7. (a) The room-temperature response and (b) the repeatability and reversibility of PANI, PANI/hollow $\mathrm{In}_{2} \mathrm{O}_{3}$ nanofiber, and PANI/hollow C\# $\operatorname{In}_{2} \mathrm{O}_{3}$ nanofiber composite sensors with exposure of 1 ppm $\mathrm{NH}_{3}$.

In order to investigate the fabricated sensor used in the detection of human breath for kidney or hepatic disease, all sensors were operated to detect the $\mathrm{NH}_{3}$ at room temperature in the concentration between $0.6 \mathrm{ppm}$ and $2.0 \mathrm{ppm}$. Figure $8 \mathrm{a}$ shows the $\mathrm{NH}_{3}$-sensing performance of the PANI, PANI/hollow $\mathrm{In}_{2} \mathrm{O}_{3}$ nanofiber, and PANI/hollow $\mathrm{C}_{2} \operatorname{In}_{2} \mathrm{O}_{3}$ nanofiber sensors. All results reveal that the response of each sensor instantaneously rose with increasing the exposure to $\mathrm{NH}_{3}$ and then, extremely, came back to the initial response value after exposure to dry air. The response of each sensor was extensively enhanced as the concentration of the analyst increased. These results represent that the response tendency of three sensors was approximately identical, but the values of response for all sensors were extremely different at the same concentration. It is clear that the PANI/hollow $\mathrm{C \# In}{ }_{2} \mathrm{O}_{3}$ nanofiber sensor possessed the highest response among the three sensors. The response values of the PANI/hollow $\mathrm{C \# In}{ }_{2} \mathrm{O}_{3}$ nanofiber sensors were correspondingly around $11.5,14.2,17.8,23.5,29.7,37.5,43.3$, and 47.3 regarding to the concentration of 0.6 , $0.8,1.0,1.2,1.4,1.6,1.8$, and $2.0 \mathrm{ppm}$. The value of response for the PANI/hollow $\mathrm{C \# In}_{2} \mathrm{O}_{3}$ nanofiber sensor exposed at $1.0 \mathrm{ppm} \mathrm{NH}_{3}$ was correspondingly about 5.74 and 1.6 times 
greater than those of PANI and PANI/hollow $\mathrm{In}_{2} \mathrm{O}_{3}$ nanofiber sensor. The fitting curves of response versus concentrations of $\mathrm{NH}_{3}$ for three sensors are shown in Figure $8 \mathrm{~b}$. According to these profiles, the correlations between the values of response and the concentrations of $\mathrm{NH}_{3}$ are approximately linear. The matching functions were correspondingly dedicated as $\mathrm{y}=2.04 \mathrm{x}+2.55, \mathrm{y}=15.23 \mathrm{x}-3.88$, and $\mathrm{y}=32.68 \mathrm{x}-14.93$ for the PANI, PANI $/$ hollow $\operatorname{In}_{2} \mathrm{O}_{3}$ nanofiber, and PANI/hollow $\mathrm{C} \# \mathrm{In}_{2} \mathrm{O}_{3}$ nanofiber sensors. The correlation coefficients, $\mathrm{R}^{2}$, were also shown in this figure. The slopes of these related lines, classified as the sensitivity of the sensors, indicate that the sensitivity of the PANI/hollow $\mathrm{C \#} \mathrm{In}_{2} \mathrm{O}_{3}$ nanofiber sensors were larger than those of PANI and PANI/hollow $\mathrm{In}_{2} \mathrm{O}_{3}$ nanofiber sensors. These results suggest that the ability to detect $\mathrm{NH}_{3}$ using the PANI/hollow $\mathrm{C} \# \mathrm{In}_{2} \mathrm{O}_{3}$ nanofiber sensor is excellent, and this composite sensor is suitable for use as a favorable material for $\mathrm{NH}_{3}$ gas detection. Table 1 shows a comparison of the sensing properties of PANI/hollow $\mathrm{C \# In}{ }_{2} \mathrm{O}_{3}$ nanofiber and formerly reported sensors from the literature. Liu et al. [20] used $\mathrm{MoS}_{2}$ nanosheets, $\mathrm{SnO}_{2}$ nanotubes, and PANI to fabricate a composite sensor containing nanostructured conformation. Their result revealed that the response value of $50 \mathrm{ppm} \mathrm{NH}_{3}$ at room temperature was 7.5, which was lower than that of our results. Li et al. [14] prepared a composite sensor using PANI and flower-like $\mathrm{WO}_{3}$ with higher special surface area. Their data indicated that the response value of $10 \mathrm{ppm} \mathrm{NH}_{3}$ at room temperature was 7.14, which was also lower than that of our results. Therefore, it is clear that the PANI/hollow $\mathrm{C \# In}_{2} \mathrm{O}_{3}$ nanofiber sensor investigated in this study showed superior sensing property to $\mathrm{NH}_{3}$ at room temperature than formerly reported sensors. Subsequently, a combination of p-type PANI and n-type hollow $\mathrm{C} \# \mathrm{In}_{2} \mathrm{O}_{3}$ nanofibers is proven as a powerful methodology for enhancing the $\mathrm{NH}_{3}$-sensing response of sensors.

The reversibility, repeatability, and selectivity of fabricated gas sensors are crucial for practicable applications. In reality, the gas sensors are generally exposed to plentiful analysts, and the target analyst is supposedly detected correctly without being affected by other analysts. The selectivity of the PANI/hollow $\mathrm{C \# In}{ }_{2} \mathrm{O}_{3}$ nanofiber sensor for ammonia, methanol, ethanol, acetone, and hexane with an exposure to the concentration of 1.0 and $2.0 \mathrm{ppm}$ is shown in Figure 9. From this result, it was clear that the PANI/hollow $\mathrm{C \# In}{ }_{2} \mathrm{O}_{3}$ nanofiber sensor contained a high-level response performance to ammonia and trimethylamine (TMA) but revealed almost no response versus other gases. The surface absorption of amine group of $\mathrm{NH}_{3}$ and TMA on the interface of the PANI/hollow $\mathrm{CHIn}_{2} \mathrm{O}_{3}$ nanofiber sensor may contribute to major mechanism of $\mathrm{NH}_{3}$ and TMA selectivity. The dedoping response between $\mathrm{NH}_{3}$ /TMA and PANI plays a significant role in enhancing $\mathrm{NH}_{3}-$ and TMA-sensing properties, indicating a selective response to $\mathrm{NH}_{3}[15,27]$. Consequently, the PANI/hollow C\#In $\mathrm{O}_{3}$ nanofiber sensor displayed excellent selectivity concerning $\mathrm{NH}_{3}$ and TMA, versus other gases at room temperature.

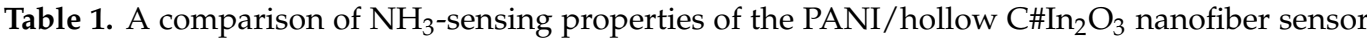
established here, and the other sensors reported previously.

\begin{tabular}{|c|c|c|c|c|c|}
\hline Materials & Gas & Conc.(ppm) & Temp. $\left({ }^{\circ} \mathrm{C}\right)$ & Response & Ref. \\
\hline $\mathrm{PANI} / \mathrm{In}_{2} \mathrm{O}_{3}$ & $\mathrm{NH}_{3}$ & 100 & RT & 3.2 & [21] \\
\hline $\mathrm{PANI} / \mathrm{ZnO}$ & $\mathrm{NH}_{3}$ & 100 & RT & 2.5 & [22] \\
\hline $\mathrm{PANI} / \mathrm{TiO}_{2}-\mathrm{SiO}_{2}$ & $\mathrm{NH}_{3}$ & 50 & RT & 10 & {$[23]$} \\
\hline $\mathrm{PANI} / \mathrm{MoS}_{2} / \mathrm{SnO}_{2}$ & $\mathrm{NH}_{3}$ & 50 & RT & 7.5 & [20] \\
\hline PANI/Graphene/ $\mathrm{SnO}_{2}$ & $\mathrm{NH}_{3}$ & 10 & RT & 2.8 & [24] \\
\hline $\mathrm{PANI} / \mathrm{WO}_{3}$ & $\mathrm{NH}_{3}$ & 10 & RT & 7.14 & {$[14]$} \\
\hline PANI/PMMA & $\mathrm{NH}_{3}$ & 1 & RT & 1.4 & [25] \\
\hline $\mathrm{PANI} / \mathrm{PEO}$ & $\mathrm{NH}_{3}$ & 1 & RT & 5 & [26] \\
\hline $\mathrm{PANI} / \mathrm{GNR} / \mathrm{In}_{2} \mathrm{O}_{3}$ nanoparticle & $\mathrm{NH}_{3}$ & 1 & RT & 10.3 & [15] \\
\hline PANI/N-GQD/hollow $\operatorname{In}_{2} \mathrm{O}_{3}$ nanofiber & $\mathrm{NH}_{3}$ & 1 & RT & 15.6 & [16] \\
\hline PANI/hollow C\#In ${ }_{2} \mathrm{O}_{3}$ nanofiber & $\mathrm{NH}_{3}$ & 1 & RT & 18.2 & This work \\
\hline
\end{tabular}



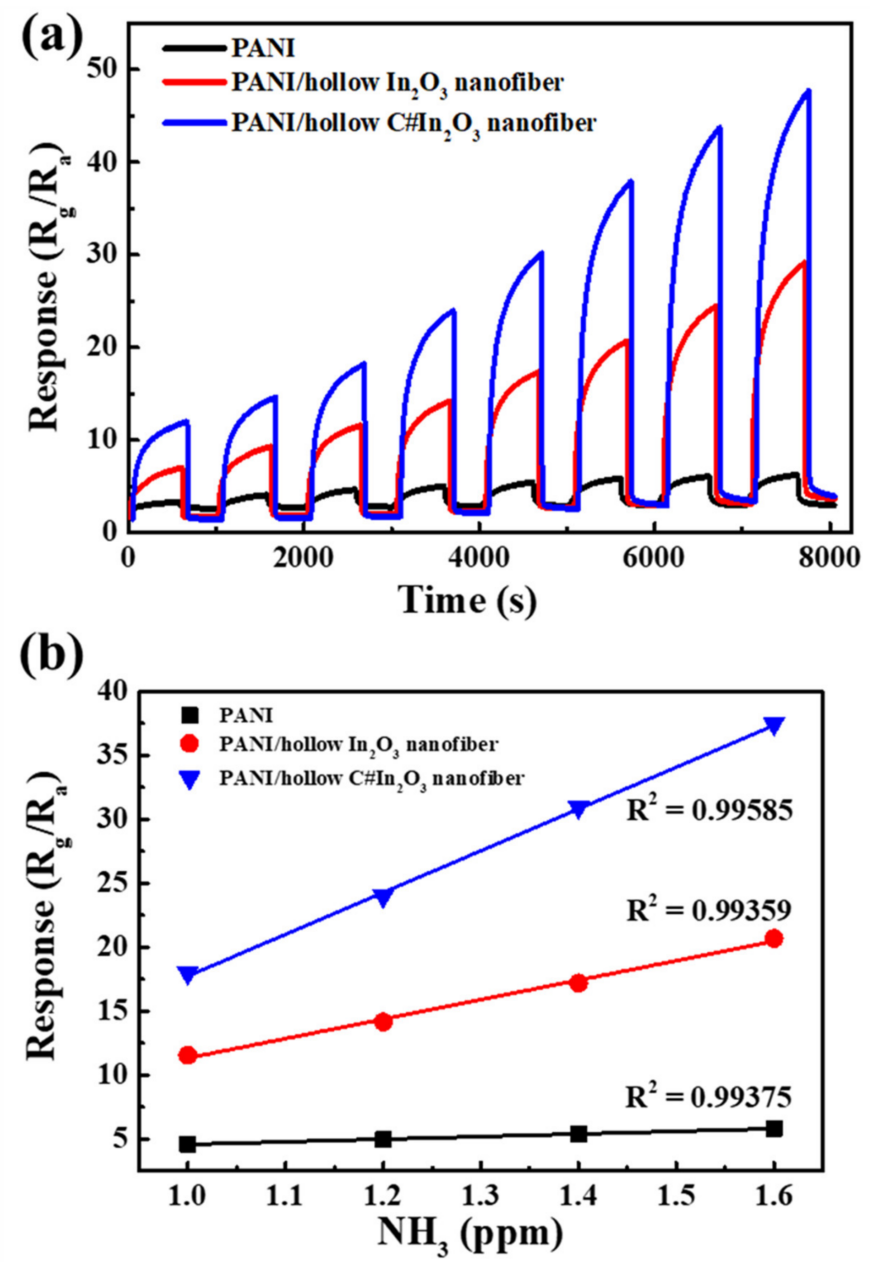

Figure 8. The (a) dynamic response-recovery curves shown in the concentration between $0.6 \mathrm{ppm}$ and $2.0 \mathrm{ppm}$, and (b) the fitting curves of response versus concentration for PANI, PANI/hollow $\mathrm{In}_{2} \mathrm{O}_{3}$ nanofiber, and PANI/hollow $\mathrm{C \#} \mathrm{In}_{2} \mathrm{O}_{3}$ nanofiber composites.

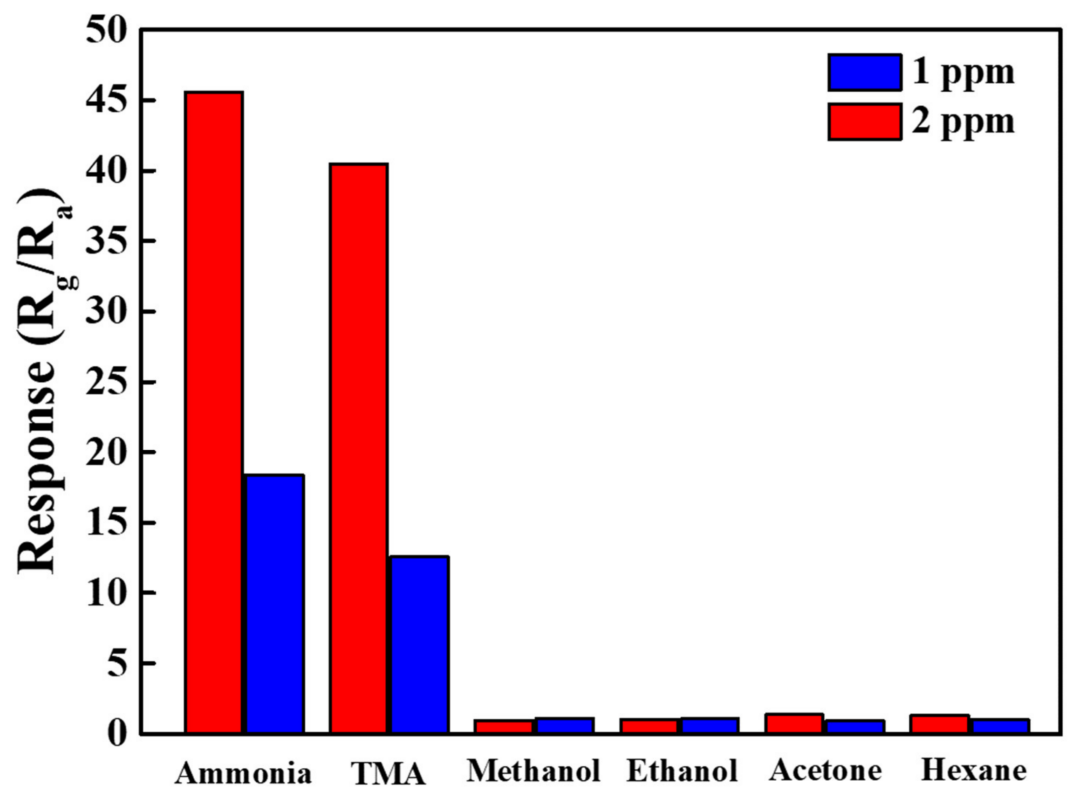

Figure 9. The selectivity of the PANI/hollow $\mathrm{C} \# \mathrm{In}_{2} \mathrm{O}_{3}$ nanofiber sensor toward $\mathrm{NH}_{3}$, trimethylamine (TMA), methanol, ethanol, acetone, and hexane with a concentration of 1 and 2 ppm. 


\section{Conclusions}

Excellent gas-sensing properties of PANI/hollow C\#In ${ }_{2} \mathrm{O}_{3}$ nanofiber composites were successfully prepared using in situ chemical oxidation polymerization. The gas-sensing performances of the fabricated PANI/hollow $\mathrm{C \# In}{ }_{2} \mathrm{O}_{3}$ nanofiber composite sensor were estimated at room temperature, and the response value of the composite sensor with an exposure of 1 ppm $\mathrm{NH}_{3}$ was 18.2, which was about 5.74 times larger than that of the pure PANI sensor. This composite sensor was demonstrated to be highly sensitive to the detection of $\mathrm{NH}_{3}$ ranging from the concentration between $0.6 \mathrm{ppm}$ and $2.0 \mathrm{ppm}$, which is critical for kidney or hepatic disease detection from the human breath. The PANI/hollow $\mathrm{C \# In}{ }_{2} \mathrm{O}_{3}$ nanofiber composite sensor also displayed superior repeatability and selectivity at room temperature with exposures of 1.0 and 2.0 ppm $\mathrm{NH}_{3}$. Owing to the outstanding selectivity and repeatability of the detection of $\mathrm{NH}_{3}$ at 1.0 and $2.0 \mathrm{ppm}$ confirmed in this investigation, the PANI/hollow $\mathrm{C \# In} \mathrm{I}_{2} \mathrm{O}_{3}$ nanofiber composite sensor will be considered as a favorable gas-sensing material for kidney or hepatic disease detection from human breath.

Author Contributions: Conceptualization, S.-Z.H. and T.-M.W.; methodology, T.-M.W.; software, S.Z.H. and Q.-Y.H.; validation, S.-Z.H. and Q.-Y.H.; formal analysis, S.-Z.H. and Q.-Y.H.; investigation, S.-Z.H. and Q.-Y.H.; resources, S.-Z.H.; data curation, S.-Z.H. and Q.-Y.H.; writing-original draft preparation, S.-Z.H. and Q.-Y.H.; writing-review and editing, T.-M.W.; visualization, T.-M.W.; supervision, T.-M.W.; project administration, T.-M.W.; funding acquisition, T.-M.W. All authors have read and agreed to the published version of the manuscript.

Funding: This work was supported by the Ministry of Science and Technology (MOST) under Grand MOST 109-2212-E-005-069-MY3 and the Ministry of Education under the project of Innovation and Development Center of Sustainable Agriculture (IDCSA).

Institutional Review Board Statement: Not applicable.

Informed Consent Statement: Not applicable.

Conflicts of Interest: The authors declare no conflict of interest.

\section{References}

1. Phillips, M.; Herrera, J.; Krishnan, S.; Zain, M.; Greenberg, J.; Cataneo, R.N. Variation in volatile organic compounds in the breath of normal humans. J. Chromatogr. B Biomed. Sci. Appl. 1999, 729, 75-88. [CrossRef]

2. Phillips, M.; Cataneo, R.N.; Cummin, A.R.C.; Gagliardi, A.J.; Gleeson, K.; Greenberg, J.; Maxfield, R.A.; Rom, W.N. Detection of lung cancer with volatile markers in the breath. Chest J. 2003, 123, 2115-2123. [CrossRef] [PubMed]

3. Haick, H.; Broza, Y.Y.; Mochalski, P.; Ruzsanyi, V.; Amann, A. Assessment, origin, and implementation of breath volatile cancer markers. Chem. Soc. Rev. 2014, 43, 1423-1449. [CrossRef]

4. Wehinger, A.; Schmid, A.; Mechtcheriakov, S.; Ledochowski, M.; Grabmer, C.; Amann, A. Lung cancer detection by proton transfer reaction mass-spectrometric analysis of human breath gas. Int. J. Mass Spectrom. 2007, 265, 49-59. [CrossRef]

5. Capuano, R.; Santonico, M.; Pennazza, G.; Ghezzi, S.; Martinelli, E.; Roscioni, C.; Lucantoni, G.; Galluccio, G.; Paolesse, R.; Natale, C.D.; et al. The lung cancer breath signature: A comparative analysis of exhaled breath and air sampled from inside the lungs. Sci. Rep. 2015, 5, 16491. [CrossRef]

6. Grabowska-Polanowska, B.; Faber, J.; Skowron, M.; Miarka, P.; Pietrzycka, A.; Sliwka, I.; Amann, A. Detection of potential chronic kidney disease markers in breath using gas chromatography with mass-spectral detection coupled with thermal desorption method. J. Chromatogr. A 2013, 1301, 179-189. [CrossRef]

7. Davies, S.; Spanel, P.; Smith, D. Quantitative analysis of ammonia on the breath of patients in end-stage renal failure. Kidney Int. 1997, 52, 223-228. [CrossRef]

8. Turner, C.; Španěl, P.; Smith, D. A longitudinal study of ammonia, acetone and propanol in the exhaled breath of 30 subjects using selected ion flow tube mass spectrometry, SIFT-MS. Physiol. Meas. 2006, 27, 321-327. [CrossRef] [PubMed]

9. Buckley, L.K.; Collins, G.E. Conductive polymer-coated fabrics for chemical sensing. Synth. Met. 1996, 78, 93-101.

10. Ciric-Marjanovic, G. Recent advances in polyaniline research: Polymerization mechanisms, structural aspects, properties and applications. Synth. Met. 2013, 177, 1-47. [CrossRef]

11. Eising, M.; Cava, C.E.; Salvatierra, R.V.; Zarbin, A.J.G.; Roman, L.S. Doping effect on self-assembled films of polyaniline and carbon nanotube applied as ammonia gas sensor. Sens. Actuators B Chem. 2017, 245, 25-33. [CrossRef]

12. Xue, L.; Wang, W.; Guo, Y.; Liu, G.; Wan, P. Flexible polyaniline/carbon nanotube nanocomposite film-based electronic gas sensors. Sens. Actuators B Chem. 2017, 244, 47-53. [CrossRef] 
13. Liu, C.; Tai, H.; Zhang, P.; Yuan, Z.; Du, X.; Xie, G.; Jiang, Y. A high-performance flexible gas sensor based on self-assembled $\mathrm{PANI}-\mathrm{CeO}_{2}$ nanocomposite thin film for trace-level $\mathrm{NH}_{3}$ detection at room temperature. Sens. Actuators B Chem. 2018, 261, 587-597. [CrossRef]

14. Li, S.; Lin, P.; Zhao, L.; Wang, C.; Liu, D.; Liu, F.; Sun, P.; Liang, X.; Liu, F.; Yan, X.; et al. The room temperature gas sensor based on polyaniline@flower-like $\mathrm{WO}_{3}$ nanocomposites and flexible PET substrate for $\mathrm{NH}_{3}$ detection. Sens. Actuators B Chem. 2018, 259, 505-513. [CrossRef]

15. Xu, L.H.; Wu, T.M. Synthesis of highly sensitive ammonia gas sensor of polyaniline/graphene nanoribbon/indium oxide composite at room temperature. J. Mater. Sci. Mater. Electron. 2020, 31, 7276-7283. [CrossRef]

16. Hong, S.Z.; Huang, Q.Y.; Wu, T.M. The room temperature highly sensitive ammonia gas sensor based on polyaniline and nitrogen-doped graphene quantum dot-coated hollow indium oxide nanofiber composite. Polymers 2021, 13, 3676. [CrossRef]

17. Topuz, F.; Abdulhamid, M.A.; Hardian, R.; Tibor Holtzl, T.; Szekely, G. Nanofibrous membranes comprising intrinsically microporous polyimides with embedded metal-organic frameworks for capturing volatile organic compounds. J. Hazard. Mater. 2022, 424, 127347. [CrossRef]

18. Alberti, S.; Andrea Dodero, A.; Sartori, E.; Vicini, S.; Ferretti, M.; Castellano, M. Composite water-borne polyurethane nanofibrous electrospun membranes with photocatalytic properties. ACS Appl. Polym. Mater. 2021, 3, 6157-6166. [CrossRef]

19. Zhang, D.; Wu, Z.; Li, P.; Zong, X.; Dong, G.; Zhang, Y. Facile fabrication of polyaniline/multi-walled carbon nanotubes/molybdenum disulfide ternary nanocomposite and its high-performance ammonia-sensing at room temperature. Sens. Actuators B Chem. 2018, 258, 895-905. [CrossRef]

20. Liu, A.; Lv, S.; Liu, F.; Hu, X.; Yang, Z.; Sun, P.; Lu, G. The gas sensor utilizing polyaniline $/ \mathrm{MoS}_{2}$ nanosheets $/ \mathrm{SnO}_{2}$ nanotubes for the room temperature detection of ammonia. Sens. Actuators B Chem. 2021, 332, 129444. [CrossRef]

21. Pang, Z.; Nie, Q.; Wei, A.; Yang, J.; Huang, F.; Wei, Q. Effect of $\operatorname{In}_{2} \mathrm{O}_{3}$ nanofiber structure on the ammonia sensing performances of $\mathrm{In}_{2} \mathrm{O}_{3}$ /PANI composite nanofibers. J. Mater. Sci. 2016, 52, 686-695. [CrossRef]

22. Talwar, V.; Singh, O.; Singh, R.C. ZnO assisted polyaniline nanofibers and its application as ammonia gas sensor. Sens. Actuators B Chem. 2014, 191, 276-282. [CrossRef]

23. Pang, Z.; Yu, J.; Li, D.; Nie, Q.; Zhang, J.; Wei, Q. Free-standing $\mathrm{TiO}_{2}-\mathrm{SiO}_{2} / \mathrm{PANI}$ composite nanofibers for ammonia sensors. J. Mater. Sci. Mater. Electron. 2017, 29, 3576-3583. [CrossRef]

24. Bera, S.; Kundu, S.; Khan, H.; Jana, S. Polyaniline coated graphene hybridized $\mathrm{SnO}_{2}$ nanocomposite: Low temperature solution synthesis, structural property and room temperature ammonia gas sensing. J. Alloy. Compd. 2018, 744, 260-270. [CrossRef]

25. Zhang, H.D.; Tang, C.C.; Long, Y.Z.; Huang, R.; Li, J.J.; Gu, C.Z. High-sensitivity gas sensors based on arranged polyaniline/PMMA composite fibers. Sens. Actuators A Phys. 2014, 219, 123-127. [CrossRef]

26. Mousavi, S.; Kang, K.; Park, J.; Park, I. A room temperature hydrogen sulfide gas sensor based on electrospun polyanilinepolyethylene oxide nanofibers directly written on flexible substrates. RSC Adv. 2016, 6, 104131-104138. [CrossRef]

27. Hsu, W.F.; Wu, T.M. Electrochemical sensor based on conductive polyaniline coated hollow tin oxide nanoparticles and nitrogen doped graphene quantum dots for sensitively detecting dopamine. J. Mater. Sci. Mater. Electron. 2019, 30, 8449-8456. [CrossRef] 